\title{
Impact of personal goals on the internal medicine R4 subspecialty match: a Q methodology study
}

\author{
Vijay J Daniels ${ }^{*}$ and Narmin Kassam
}

\begin{abstract}
Background: There has been a decline in interest in general internal medicine that has resulted in a discrepancy between internal medicine residents' choice in the R4 subspecialty match and societal need. Few studies have focused on the relative importance of personal goals and their impact on residents' choice. The purpose of this study was to assess if internal medicine residents can be grouped based on their personal goals and how each group prioritizes these goals compared to each other. A secondary objective was to explore whether we could predict a resident's desired subspecialty choice based on their constellation of personal goals.

Methods: We used Q methodology to examine how postgraduate year 1-3 internal medicine residents could be grouped based on their rankings of 36 statements (derived from our previous qualitative study). Using each groups' defining and distinguishing statements, we predicted their subspecialties of interest. We also collected the residents' first choice in the subspecialty match and used a kappa test to compare our predicted subspecialty group to the residents' self-reported first choice.

Results: Fifty-nine internal medicine residents at the University of Alberta participated between 2009 and 2010 with $46 \mathrm{Q}$ sorts suitable for analysis. The residents loaded onto four factors (groups) based on how they ranked statements. Our prediction of each groups' desired subspecialties with their defining and/or distinguishing statements are as follows: group 1 - general internal medicine (variety in practice); group 2 - gastroenterology, nephrology, and respirology (higher income); group 3 - cardiology and critical care (procedural, willing to entertain longer training); group 4 - rest of subspecialties (non-procedural, focused practice, and valuing more time for personal life). There was moderate agreement (kappa $=0.57$ ) between our predicted desired subspecialty group and residents' self-reported first choice $(p<0.001)$.

Conclusion: This study suggests that most residents fall into four groups based on a constellation of personal goals when choosing an internal medicine subspecialty. The key goals that define and/or distinguish between these groups are breadth of practice, lifestyle, desire to do procedures, length of training, and future income potential. Using these groups, we were able to predict residents' first subspecialty group with moderate success.
\end{abstract}

Keywords: Career choice, Internal medicine, Q methodology, Postgraduate medical education, Specialization, Canada

\section{Background}

There is a discrepancy between societal need for general internal medicine specialists and internal medicine residents' choice in the R4 subspecialty match [1-7]. There has been a decline in internal medicine residents' interest in general internal medicine in the United States with 54\% planning to practice general internal medicine in 1998 [8] compared with $22 \%$ from survey data collected from 2008 to 2011 [9]. There are similar concerns in South Asia [4]

* Correspondence: vdaniels@ualberta.ca

Department of Medicine, University of Alberta, Edmonton, Canada and in several European countries [5-7]. In Canada, internal medicine residency training begins with three years of core internal medicine, and then all residents apply and match (known as the R4 match) to a subspecialty residency with general internal medicine as one of those options. Between 2008 and 2010, 21-24\% of internal medicine residents pursued general internal medicine based on Canadian Post M.D. Education Registry (CAPER) data [10]. Concurrently, Canadian physician resource studies predicted 400-500 general internists would retire between 2010 and 2013 with the number of new graduates only
C Biomed Central

(c) 2013 Daniels and Kassam; licensee BioMed Central Ltd. This is an open access article distributed under the terms of the Creative Commons Attribution License (http://creativecommons.org/licenses/by/2.0), which permits unrestricted use, distribution, and reproduction in any medium, provided the original work is properly cited. 
meeting half of this demand, let alone the current deficit in many areas of the country and the expected population growth [11].

There have been several studies published examining demographic and non-demographic aspects associated with internal medicine residents' choice of subspecialty [8,12-21]. However, few have looked at the relative importance of personal goals and their impact on the internal medicine R4 subspecialty match $[8,14,16]$. These studies examined personal goals based on career path with participants being surveyed with either dichotomous (yes or no) items [8] or five-point likert scales [14,16]. Although these approaches can answer the question, "Does this group value lifestyle?", they may not be the ideal methods to answer the question "How high of a priority is lifestyle for this group as compared to others?" as there is nothing that forces respondents to prioritize the items they answer.

The purpose of this study was to assess if internal medicine residents can be grouped based on their personal goals and how each group prioritizes these goals compared to each other. A secondary objective was to explore whether we could predict a resident's desired subspecialty choice based on their constellation of personal goals.

\section{Methods}

\section{Study setting}

This study was conducted at the University of Alberta with postgraduate year (PGY) one to three internal medicine residents.

\section{Design}

The design framework was $\mathrm{Q}$ methodology invented in 1935 by British physicist-psychologist William Stephenson to allow quantitative analysis of subjective matters [22]. Cross [23] describes Q methodology as the ideal method to measure attitudes as it involves a forced distribution greatly limiting the number of uncertain responses as compared to a likert scale. Q methodology involves the sorting of statements (the $\mathrm{Q}$ set) into columns of Agree to Disagree and then $\mathrm{Q}$ sets are analyzed with a factor analysis. However unlike traditional factor analysis where items are loaded onto a factor, in Q methodology, the respondents are loaded onto a factor. This results in factors or groups of respondents who ranked statements similarly. The output of these analyses is accompanied by standard scores (z-scores) for each statement for a given factor.

\section{Q set}

We began with all of the quotes from our previous qualitative study [19], and each author independently created a set of representative statements. The authors then discussed the statements and created a list of 36 representative statements (see Table 1). These statements were then placed into a score sheet with a quasinormal distribution (see Figure 1).

\section{Table $1 \mathrm{Q}$ set (statements included in the $Q$ sort)}

\section{Statement}

1. My decision is based on the physiology of the subspecialty.

2. GIM doesn't get any of the interesting single organ diseases.

3. The patients in my subspecialty of interest are fascinating.

4. I really like the general medicine population of patients.

5. I prefer to be an expert in my area.

6. With the amount of knowledge, you cannot keep up with GIM.

7. GIM patients are too complex.

8. The positive interactions I have had with attendings affected my decision.

9. The negative interactions I have had with attendings affected my decision.

10. My decision is predominantly based on experiences as a medical student.

11. My decision is predominantly based on experiences as a resident.

12. I value more time for my personal life.

13. Lifestyle and more control over my practice are important.

14. I want to be in a field that is in demand.

15. I am focused on my job prospects.

16. I want to be in a large city.

17. I want to work in a smaller community.

18. The resources of a fellowship program are important.

19. The skills I need are easier to attain from a subspecialty fellowship than a GIM fellowship.

20. I want something that pays well given how long l've trained.

21. I like a little bit of everything and variety.

22. Some specialties are not fairly remunerated \& this is an important consideration.

23. I prefer an outpatient-based practice.

24. I prefer an inpatient-based practice.

25. I'd like to do a combination of inpatient and outpatient.

26. I enjoy procedures.

27. I want to do procedures as part of my practice.

28. I want to be done after five years of residency.

29. I am willing to do as many years as it takes to get the job and subspecialty I want

30. I like the fact you can save 1+ years in GIM.

31. A two-year GIM fellowship is a deterrent.

32. The fact that subspecialists can also be general internists is important to me.

33. Prestige and respect from colleagues matter to me.

34. Prestige and respect from the public matter to me.

35. I want to be valued in what I'm doing

36. GIM is a dumping ground for patients nobody wants. 


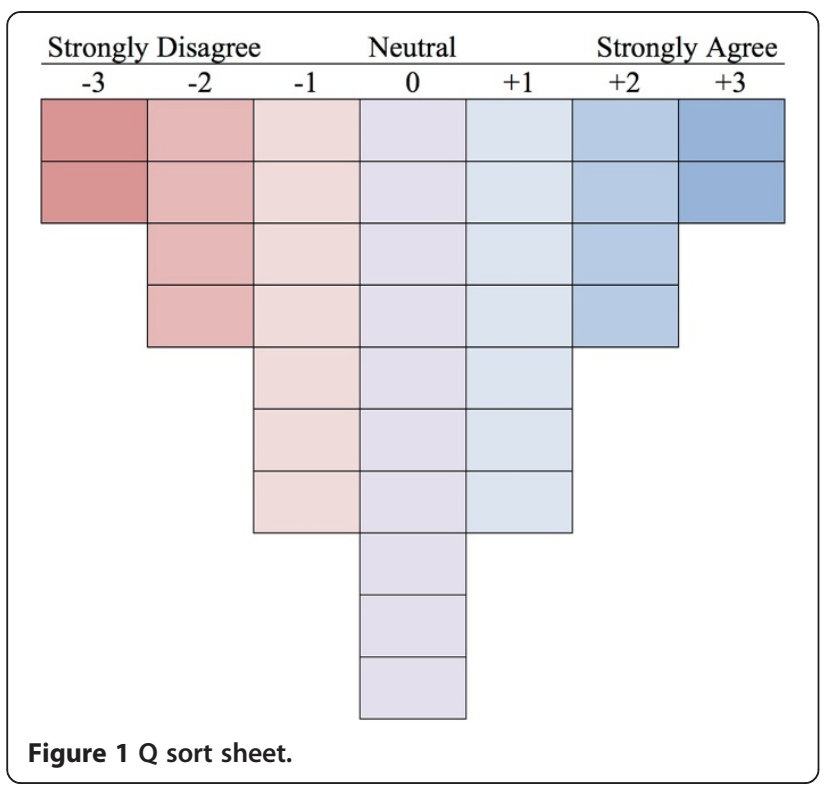

Study participants and data collection procedures

Ethics approval for the study was granted by the Health Research Ethics Board - Panel B at the University of Alberta. With permission of the internal medicine residency program, we approached the PGY-1 to PGY-3 internal medicine residents at one of their Academic HalfDays at the start of the 2009 academic year to explain the project and ask for volunteers to participate in our study. Consenting participants were given randomly sorted cards, each with one of the 36 statements. They were first asked to rank the 36 statements into levels of agreement and disagreement. Each participant then entered the number corresponding to each statement onto the score sheet (see Figure 1). Each Q-sort was considered adequate for analysis if all statements were used exactly once.

Participants were also asked to indicate their first three desired subspecialties and enter demographic information such as age range, gender, year of residency, and highest level of education (Bachelor's, Master's, Ph.D.). The procedure was repeated at the start of the 2010 academic year to include residents who were not present at the 2009 session (those that missed the session and new residents to the program).

\section{Data analysis}

As mentioned previously, Q Methodology uses a factor analysis, but instead of grouping items measuring a similar construct, it groups respondents who rank statements similarly. PQMethod 2.11 [24] was used to enter and analyze the Q sort data. We performed factor analysis by principal component analysis with subsequent varimax rotation and compared the rotations of three to six factors choosing the most adequate solution. Adequacy is determined individually for a study [25]; we felt the most adequate solution would: 1) balance between maximizing the respondents loading onto factors with the variance explained, and 2) be judged by three independent evaluators (V.J.D., N.K., D.B.R.) as appearing internally consistent. This latter decision was based on the sorted statements that are defining statements and distinguishing statements for that factor. Defining statements are those with z-scores greater than +1 (factor agreed with these statements) or less than -1 (factor disagreed with these statements), and distinguishing statements are those that a particular factor agreed or disagreed statistically more strongly than other factors [26].

Once we had identified the number of factors, the same three independent evaluators examined each factor's defining and distinguishing statements to predict the desired subspecialties of the residents that loaded onto a factor. To make these predictions, two of the evaluators (D.B.R. and N.K.) used their experiences as residency program directors for core internal medicine and general internal medicine respectively in which they counselled many residents on their selection of residency program, and the third evaluator (V.J.D.) used recent experiences as a resident and discussions with colleagues during training. Each

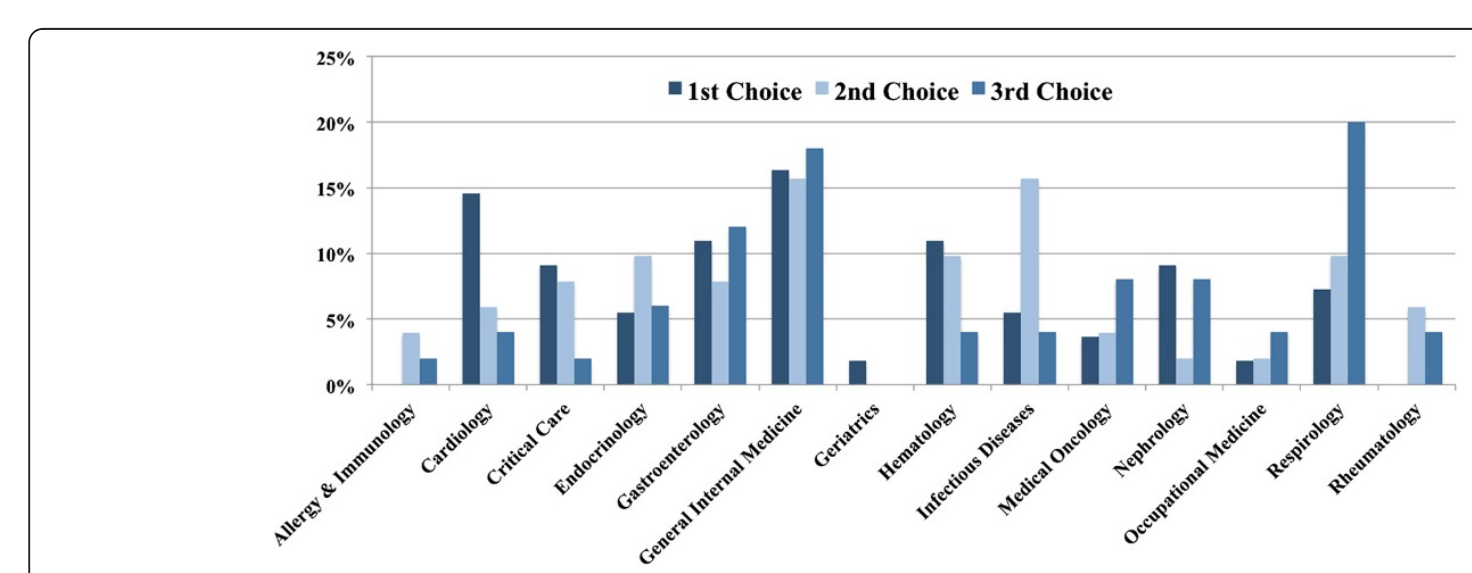

Figure 2 Desired choice of subspecialty. 
Table 2 Number of factors rotated with number of $Q$ sorts loaded and variance explained

\begin{tabular}{lcccc}
\hline & \multicolumn{4}{c}{$\begin{array}{c}\text { Number of } \\
\text { factors rotated }\end{array}$} \\
\cline { 2 - 5 } & $\mathbf{3}$ & $\mathbf{4}$ & $\mathbf{5}$ & $\mathbf{6}$ \\
\hline $\begin{array}{l}\text { \# of Q sorts that loaded onto factors } \\
\text { (total 46) }\end{array}$ & 29 & 35 & 34 & 27 \\
Variance explained & $48 \%$ & $54 \%$ & $59 \%$ & $63 \%$ \\
\hline
\end{tabular}

evaluator predicted subspecialties for each factor, and then discussed their thoughts with any disagreements resolved by consensus. We used SPSS v.21 [27] to calculate a kappa coefficient to analyze for agreement between our predicted subspecialty group and the residents' self-reported first desired subspecialty group. We also performed Mann Whitney $U$ tests to assess differences in age grouping, year of residency, and level of education, and chi-squared tests to assess for differences in gender and first subspecialty choice between participants who were included in the comparison of predicted and self-reported subspecialty group and those who were not.

\section{Results}

In 2009, 43 residents participated with an additional 16 in 2010 (total 59) out of a possible 114 residents. Thirteen Q sorts were excluded because of either missing or duplicate statements resulting in $46 \mathrm{Q}$ sorts suitable for analysis. Residents were primarily 26 to 31 years old (63\% of participants), with $16 \%$ younger than 26 years old and $21 \%$ older than 31 years old. The majority (63\%) were female, and $42 \%$ were in PGY-1, $28 \%$ in PGY-2 and $30 \%$ in PGY-3. Nine percent of participants did not have a premedical degree, $63 \%$ had a bachelor's degree and $28 \%$ had a master's degree. Participants desired choice of subspecialties is shown in Figure 2.

We compared the different solutions from rotating three to six factors in terms of number of $\mathrm{Q}$ sorts that loaded onto a factor and percentage of variance explained (see

Table 3 Defining and distinguishing statements for factor $1(n=8)$

\begin{tabular}{|c|c|c|c|}
\hline No. & Statement & Rank & Z-score \\
\hline \multicolumn{4}{|c|}{ Defining statements } \\
\hline \multicolumn{4}{|c|}{ Agrees strongly with the following statements } \\
\hline 21 & I like a little bit of everything and variety & 3 & 2.71 \\
\hline 13 & Lifestyle and more control over my practice are important & 3 & 1.81 \\
\hline 12 & I value more time for my personal life & 2 & 1.38 \\
\hline 25 & I'd like to do a combination of inpatient and outpatient & 2 & 1.15 \\
\hline 27 & I want to do procedures as part of my practice & 2 & 1.08 \\
\hline \multicolumn{4}{|c|}{ Disagrees strongly with the following statements } \\
\hline 24 & I prefer an inpatient-based practice & -2 & -1.07 \\
\hline 9 & The negative interactions with attendings were important & -2 & -1.18 \\
\hline 29 & I am willing to do as many years as it takes to get the job and subspecialty I want & -2 & -1.30 \\
\hline 6 & With the amount of knowledge, you can not keep up with GIM & -3 & -1.31 \\
\hline 2 & GIM doesn't get any of the interesting single organ diseases & -3 & -1.99 \\
\hline
\end{tabular}

\section{Distinguishing statements}

Agrees with the following statements more than other factors

\begin{tabular}{|c|c|c|c|}
\hline 21 & I like a little bit of everything and variety & 3 & $2.71^{*}$ \\
\hline 4 & I really like the general medicine population of patients & 1 & 0.78 \\
\hline 7 & GIM patients are too complex & 0 & $0.30^{*}$ \\
\hline 17 & I want to work in a smaller community & 0 & $-0.17^{*}$ \\
\hline \multicolumn{4}{|c|}{ Disagrees with the following statements more than other factors } \\
\hline 35 & I want to be valued in what I'm doing & 0 & 0.48 \\
\hline 5 & I prefer to be an expert in my area & 0 & $-0.22^{*}$ \\
\hline 32 & The fact that subspecialists can also be general internists is important to me & -1 & $-0.61^{*}$ \\
\hline 16 & I want to be in a large city & -1 & $-0.71^{*}$ \\
\hline 24 & I prefer an inpatient-based practice & -2 & $-1.07^{*}$ \\
\hline 2 & GIM doesn't get any of the interesting single organ diseases & -3 & -1.99 \\
\hline
\end{tabular}


Table 2). We deemed four or five factors to have the adequate number of $\mathrm{Q}$ sorts and percentage of variance explained. The three evaluators (V.J.D., N.K. and D.B.R.) independently reviewed each solution based on each factor's defining and distinguishing statements; each evaluator felt the four-factor solution was the most appropriate.

The key statements that define and/or distinguish between these factors are breadth of practice, lifestyle, desire to do procedures, length of training, and future income potential. Three statements with the most agreement between factors are as follows: "I'd like to do a combination of inpatient and outpatient" (moderate agreement from the four factors); "My decision was predominantly based on experiences as a medical student" (mild disagreement from the four factors); and "Prestige and respect from colleagues matters to me" (scored as neutral by all four factors). The three statements with the most disagreement between factors were: "I am willing to do as many years as it takes to get the job and subspecialty I want" (moderate agreement by factor 3 but disagreement from all other factors); "I like a little bit of everything and variety" (strong agreement from factor 1 , mild agreement or neutral from other factors); and "A two-year GIM fellowship is a deterrent" (mild agreement from factor 2 but disagreement from other factors).

The three evaluators reviewed the defining and distinguishing statements (see Tables 3, 4, 5 and 6) and predicted that factor 1 represents those interested in general internal medicine (variety as the top priority), factor 2 represents gastroenterology, nephrology, and respirology (higher income), factor 3 represents cardiology and critical care (longer training, less concern with time for personal life), and factor 4 represents the rest of the subspecialties (lower income, non-procedural subspecialties). Although

Table 4 Defining and distinguishing statements for factor $2(n=9)$

\begin{tabular}{llll}
\hline No. & Statement & Rank & Z-score \\
\hline Defining statements & 3 & 3 & 2 \\
Agrees strongly with the following statements & 2 & 1.59 \\
12 & I value more time for my personal life & 2 & 1.53 \\
16 & I want to be in a large city & 2 & 1.13 \\
32 & The fact that subspecialists can also be general internists is important to me & 2 & 1.12 \\
20 & I want something that pays well given how long we've trained & 1 & 1.10 \\
25 & I'd like to do a combination of inpatient and outpatient & 1 & 1 \\
13 & Lifestyle and more control over my practice are important & 1.04 \\
31 & A two-year GIM fellowship is a deterrent & 1.02 \\
35 & I want to be valued in what I'm doing & -2 & -2 \\
14 & I want to be in a field that is in demand & -2 & -1.01 \\
Disagrees strongly & with the following statements & -2 \\
36 & GIM is a dumping ground for patients nobody wants & -3 & -3 \\
9 & The negative interactions with attendings were important & -1.33 \\
7 & GIM patients are too complex & -1.33 \\
23 & I prefer an outpatient-based practice & I am willing to do as many years as it takes to get the job and subspecialty I want & -2.33 \\
17 & I want to work in a smaller community & & -2
\end{tabular}

\section{Distinguishing statements}

Agrees with the following statements more than other factors

\begin{tabular}{|c|c|c|c|}
\hline 16 & I want to be in a large city & 3 & $1.53^{*}$ \\
\hline 32 & The fact that subspecialists can also be general internists is important to me. & 2 & $1.20^{*}$ \\
\hline 31 & A two-year GIM fellowship is a deterrent & 1 & $1.04^{*}$ \\
\hline 22 & Some specialties are not fairly remunerated and this is an important consideration & 1 & $0.76^{*}$ \\
\hline \multicolumn{4}{|c|}{ Disagrees with the following statements more than other factors } \\
\hline 18 & The resources of a fellowship program are important & -1 & -0.51 \\
\hline 11 & My decision was predominantly based on experiences as a resident & -1 & $-0.90^{*}$ \\
\hline 20 & I am willing to do as many years as it takes to get the job and subspecialty I want & -3 & $-1.93^{*}$ \\
\hline
\end{tabular}

Factor 2 predicted to represent those interested in gastroenterology, nephrology, \& respirology. All distinguishing statements are $\mathrm{p}<0.05$ and * indicates $\mathrm{p}<0.01$. 
35 residents loaded onto a factor, one did not provide their desired subspecialty. For the remaining 34 residents there was moderate agreement (kappa $=0.57, \mathrm{p}<0.001$ ) between our predictions of what each factor would choose as their subspecialty group and residents' self-reported first desired subspecialty (see Table 7). There were no differences in age $(p=0.13)$, year of residency $(p=0.18)$, level of education $(p=0.66)$, gender $(p=0.72)$ or first subspecialty choice $(\mathrm{p}=0.55)$ between participants who were included in the comparison of predicted and self-reported subspecialty group and those who were not.

\section{Discussion}

The purpose of this study was to evaluate if we could group residents based on how they prioritized their personal goals for their career, and we were able to group 35 of 46 residents $(76 \%)$ to one of four groups. Using these personal goals groups, we had moderate agreement $($ kappa $=0.57)$ between our predicted subspecialty group and residents' self-reported first desired subspecialty, something that we have not seen in our review of the literature.

The main advantage of $\mathrm{Q}$ methodology is that it forces a quasi-normal distribution so respondents cannot select the same response for every item, as they can with traditional survey methods. Horn and colleagues' [14] Canadian survey study grouped their respondents based on subspecialties (procedural, non-procedural, and non-procedural with declining interest) and found that all three groups valued diversity of clinical spectrum. We found that only one group valued variety compared to other groups. Similarly, Horn and colleagues [14] found their three groups all valued satisfaction among staff physicians whereas only one of our groups valued positive interactions with attending physicians. Although we are not comparing the exact same statements, the differences between these two studies are likely attributable to the methodology, with $\mathrm{Q}$ methodology allowing better differentiation between groups.

\section{Table 5 Defining and distinguishing statements for factor $3(n=7)$}

\begin{tabular}{|c|c|c|c|}
\hline No. & Statement & Rank & Z-score \\
\hline \multicolumn{4}{|c|}{ Defining statements } \\
\hline \multicolumn{4}{|c|}{ Agrees strongly with the following statements } \\
\hline 5 & I prefer to be an expert in my area & 3 & 1.50 \\
\hline 35 & I want to be valued in what I'm doing & 3 & 1.44 \\
\hline 29 & I am willing to do as many years as it takes to get the job and subspecialty I want & 2 & 1.38 \\
\hline 1 & My decision is based on the physiology of the subspecialty & 2 & 1.37 \\
\hline 36 & GIM is a dumping ground for patients nobody wants & 2 & 1.32 \\
\hline 27 & I want to do procedures as part of my practice & 2 & 1.12 \\
\hline \multicolumn{4}{|c|}{ Disagrees strongly with the following statements } \\
\hline 28 & I want to be done after five years of residency & -1 & -1.13 \\
\hline 2 & GIM doesn't get any of the interesting single organ diseases & -2 & -1.25 \\
\hline 23 & I prefer an outpatient-based practice & -2 & -1.30 \\
\hline 6 & With the amount of knowledge, you can not keep up with GIM & -2 & -1.45 \\
\hline 31 & A two-year GIM fellowship is a deterrent & -2 & -1.79 \\
\hline 30 & I like the fact you can save $1+$ years in GIM & -3 & -1.88 \\
\hline 17 & I want to work in a smaller community & -3 & -1.89 \\
\hline
\end{tabular}

\section{Distinguishing statements}

Agrees with the following statements more than other factors

29 I am willing to do as many years as it takes to get the job and subspecialty I want.

1 My decision is based on the physiology of the subspecialty

36 GIM is a dumping ground for patients nobody wants

Disagrees with the following statements more than other factors

\begin{tabular}{|c|c|c|c|}
\hline 12 & I value more time for my personal life & 0 & $-0.03^{*}$ \\
\hline 28 & I want to be done after five years of residency & -1 & $-1.13^{*}$ \\
\hline 31 & A two-year GIM fellowship is a deterrent & -2 & $-1.79^{*}$ \\
\hline 3 & I like the fact you can save $1+$ years in GIM & -3 & $-1.88^{*}$ \\
\hline
\end{tabular}


Examining the four groups of residents (see Tables 3, 4, 5 and 6), there are some key findings. It has been established in medical students that interest in a specialty correlates strongly with future income [28]. In internal medicine, a common finding across studies is that subspecialties such as cardiology, gastroenterology, hospitalists, nephrology, and respirology value a higher remuneration more than other subspecialties. We found that the group of residents interested in gastroenterology, nephrology and respirology valued remuneration more than others, but this was not the driver for those interested in cardiology or general internal medicine (which in Canada is somewhat similar to a hospitalist in the United States). The primary driver for those interested in cardiology and critical care was willingness to extend training, which is consistent with our anecdotal experience of these residents often doing seven, eight or sometimes more years of residency before ending training.

In our previous qualitative study [19], we often heard residents referring to general internal medicine as a dumping ground for patients other subspecialties did not want. In this study, it would appear that this sentiment is only a strong motivator for those interested in cardiology and critical care and was not a major concern for the other groups. In Canada, we have recently moved from a one to two-year general internal medicine fellowship after three core years of internal medicine. Our previous study indicated this increased length of training may be a deterrent to pursuing general internal medicine, and we have now found that this applies mainly to those interested in gastroenterology, nephrology and respirology.

In the current study, it was hard to tease out the nonprocedural lower income subspecialties from each other, which may be due to a smaller sample size. However, this may also be due to a similar set of goals with these residents: they do not want to do procedures, are not as concerned with income, and want a focused area of expertise. What may distinguish them from each other is the specific patients whom they are interested seeing and the positive and negative interactions the residents have had with attending physicians.

Table 6 Defining and distinguishing statements for factor $4(n=11)$

\begin{tabular}{|c|c|c|c|}
\hline No. & Statement & Rank & Z-score \\
\hline \multicolumn{4}{|c|}{ Defining statements } \\
\hline \multicolumn{4}{|c|}{ Agrees strongly with the following statements } \\
\hline 5 & I prefer to be an expert in my area & 3 & 1.95 \\
\hline 13 & Lifestyle and more control over my practice are important & 3 & 1.92 \\
\hline 12 & I value more time for my personal life & 2 & 1.62 \\
\hline 3 & The patients in my subspecialty of interest are fascinating & 2 & 1.45 \\
\hline 35 & I want to be valued in what I'm doing & 2 & 1.41 \\
\hline 8 & The positive interactions with attendings were important & 2 & 1.36 \\
\hline \multicolumn{4}{|c|}{ Disagrees strongly with the following statements } \\
\hline 22 & Some specialties are not fairly remunerated and this is an important consideration & -2 & -1.04 \\
\hline 17 & I want to work in a smaller community & -2 & -1.05 \\
\hline 27 & I want to do procedures as part of my practice & -2 & -1.33 \\
\hline 2 & GIM doesn't get any of the interesting single organ diseases & -2 & -1.47 \\
\hline 7 & GIM patients are too complex & -3 & -1.53 \\
\hline 26 & I enjoy procedures & -3 & -1.74 \\
\hline
\end{tabular}

\section{Distinguishing statements}

Agrees with the following statements more than other factors

\begin{tabular}{|c|c|c|c|}
\hline 3 & The patients in my subspecialty of interest are fascinating & 2 & 1.45 \\
\hline 8 & The positive interactions with attendings were important & 2 & $1.36^{*}$ \\
\hline 28 & I want to be done after five years of residency & 1 & $0.58^{*}$ \\
\hline 9 & The negative interactions with attendings were important & 0 & $0.23^{*}$ \\
\hline \multicolumn{4}{|c|}{ Disagrees with the following statements more than other factors } \\
\hline 20 & I want something that pays well given how long we've trained & 0 & $-0.63^{*}$ \\
\hline 27 & I want to do procedures as part of my practice & -2 & $-1.33^{*}$ \\
\hline 26 & I enjoy procedures & -3 & $-1.74^{*}$ \\
\hline
\end{tabular}

Factor 4 predicted to represent those interested in non-procedural, lower income subspecialties. All distinguishing statements are $\mathrm{p}<0.05$ and * indicates $\mathrm{p}<0.01$. 
Table 7 Agreement of predicted subspecialty group and self-reported first desired subspecialty group

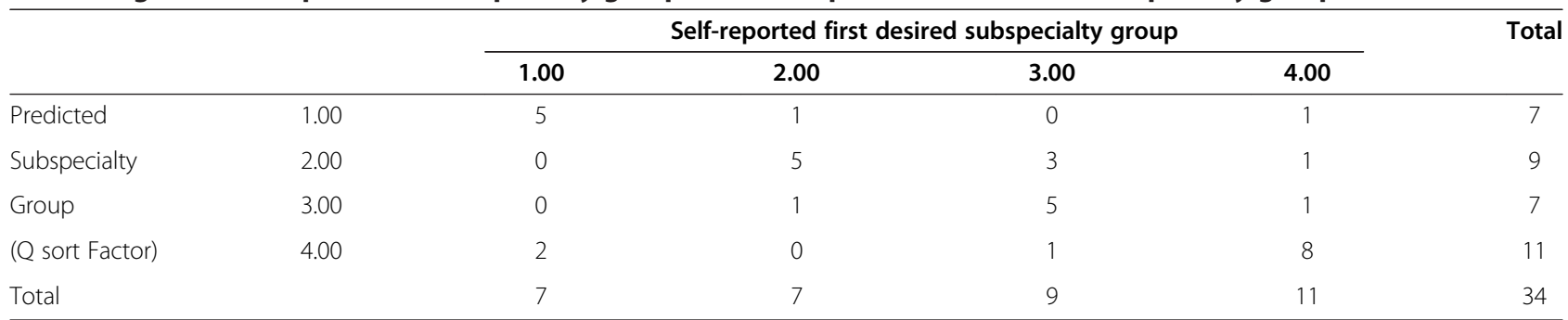

Kappa $=0.57, \mathrm{p}<0.001$.

Because this study was done with Canadian residents, it is worth noting the similarities and differences in the practice of general internal medicine in Canada compared to other countries. Ghali and colleagues [29] reviewed the clinical profile of general internal medicine in Argentina, Australia, Canada, Japan, New Zealand, Switzerland, and the United States. General internal medicine in Canada is a consultative service to primary care practitioners and is often hospital based caring for complex, multisystem patients. This overall profile is similar to that of general internists in Australia and New Zealand, and somewhat similar to general internists in Switzerland. This differs from general internists in the United States, Argentina and Japan who often have a large outpatient primary care role, though many also have consultative and hospitalist roles.

That said, one of the most interesting findings of our study is why a resident desires a career in general internal medicine. It is not surprising this group enjoys variety but what is surprising is this is essentially the sole driver for choosing general internal medicine over other subspecialties as exhibited by the extremely high Z-score of 2.71. A past president of the Canadian Society of Internal Medicine may have put it best when he said, "To my mind, this clinical smorgasbord is the best advertisement for doing general internal medicine" [30]. Regardless of the differences in the clinical profile of general internal medicine globally, this thirst for variety as a driver for residents to pursue general internal medicine is likely to transcend geographical borders.

\section{Limitations and future directions}

This study was undertaken using residents at one internal medicine residency program in Canada and thus the results may be different at other institutions across Canada or in other countries. We were able to sample 59 (52\%) of the 114 eligible residents; however, 13 did not complete the $\mathrm{Q}$ sort successfully. This resulted in only 46 participants of whom 11 did not load onto a factor and one did not complete their desired subspecialty, so they could not be included in our prediction of subspecialty compared to self-reported desired subspecialty. Though the demographics of the remaining 34 participants appear similar to the rest, this reduction in participants may reduce the generalizability of our findings. Finally, the statements used, though diverse, did not incorporate every possible personal goal such as desire for long versus short-term relationships with patients, debt load when entering residency, interest in specific issues such as health care policy, or desire for an academic versus non-academic career.

A future Q methodology study could involve residents across Canada, which might allow us to get at a more granular level (possibly 14 factors that could predict the individual subspecialties). Future research could also incorporate personal goals that were missing from this study, and could be done in a computerized format to prevent missing data. This would be helpful to further elucidate the impact of personal goals on residents' choice in the R4 subspecialty match.

\section{Conclusion}

Although previous aspects identified in the literature are important, this study suggests that residents fall into four groups based on a constellation of personal goals when choosing an internal medicine subspecialty. The key goals that define and/or distinguish between these groups are breadth of practice, lifestyle, desire to do procedures, length of training, and future income potential. Using these personal goals groups, we were able to predict residents' first subspecialty choice/group with moderate success.

\section{Competing interests}

The authors declare they have no competing interests, financial or other.

\section{Authors' contributions}

All authors listed have contributed sufficiently to the project to be included as authors, and all those who are qualified to be authors are listed in the author byline. NK conceived the original idea for the project. VJD worked on the design of the project with the input of NK. VJD carried out the data collection and analysis. VJD drafted the first version and subsequent revisions of the manuscript; NK reviewed and edited the various versions of the manuscript. Both authors approved the final draft.

Acknowledgements

The authors wish to thank Dr. Darryl B. Rolfson for his assistance in selecting the number of factors and grouping subspecialties by factor.

Received: 26 April 2013 Accepted: 18 December 2013

Published: 21 December 2013 


\section{References}

1. American College of Physicians: Creating a new national workforce for internal medicine. http://www.acponline.org/advocacy/where_we_stand/ policy/im_workforce.pdf.

2. Association of American Medical Colleges: The complexities of physician supply and demand: projections through 2025. https://members.aamc. org/eweb/upload/The\%20Complexities\%20of\%20Physician\%20Supply.pdf. Accessed March 20, 2013.

3. Canadian Society of Internal Medicine: "Care-Fully" Defining a Plan for General Internal Medicine in Canada. 2005. [http://www.csimonline.com], Accessed December 23, 2008

4. Patel MJ, Riaz M, Tariq M, Jamil S, Ansari T, Khan MS, Samdani AJ, Ayaz SI, Sorathia A, Akhtar J: Career goals of trainee physicians in internal medicine. J Coll Physicians Surg Pak 2008, 18(6):352-356.

5. Puchner R: Job satisfaction and prospects of internal medicine specialists in Austria-an analysis of the profession. Wien Klin Wochenschr 2007, 119(17-18):503-511.

6. Stuyt PM, de Graaf J, van der Meer JW: Who does become an internist? Neth J Med 2004, 62(3):98-101.

7. Waeber G, Cornuz J, Gaspoz JM, Pécoud A, Perrier A: Perspectives and challenges to guarantee training and renewal in general internal medicine. Rev Med Suisse 2009, 5(188):232-236.

8. Garibaldi RA, Popkave C, Bylsma W: Career plans for trainees in internal medicine residency programs. Acad Med 2005, 80(5):507-512.

9. West CP, Dupras DM: General medicine vs subspecialty career plans among internal medicine residents. JAMA 2012, 308(21):2241-2247.

10. Canadian post-MD education registry. [http://www.caper.ca]: Available from: http://www.caper.ca/download_publications_en.php. Accessed March 19, 2012.

11. McAlister FA: In search of shakespeareans. CJGIM 2010, 5(4):149.

12. Grosso $\amalg$, Goode LD, Kimball HR, Kooker DJ, Jacobs C, Lattie G: The subspecialization rate of third year internal medicine residents from 1992 through 1998. Teach Learn Med 2004, 16(1):7-13.

13. Diehl AK, Kumar V, Gateley A, Appleby JL, O'Keefe ME: Predictors of final specialty choice by internal medicine residents. J Gen Intern Med 2006 21(10):1045-1049.

14. Horn L, Tzanetos K, Thorpe K, Straus SE: Factors associated with the subspecialty choices of internal medicine residents in Canada. BMC Med Educ 2008, 8:37.

15. McDonald FS, West CP, Popkave C, Kolars JC: Educational debt and reported career plans among internal medicine residents. Ann Intern Med 2008, 149(6):416-420.

16. West CP, Drefahl MM, Popkave C, Kolars JC: Internal medicine resident selfreport of factors associated with career decisions. J Gen Intern Med 2009, 24(8):946-949.

17. Katz SJ, Yacyshyn EA: Attracting internal medicine trainees to rheumatology: where and when programs should focus efforts. J Rheumatol 2009, 36(12):2802-2805.

18. Ofoma UR, Lehman EE, Haidet $P$, Yacht A: Associations between subspecialty fellowship interest and knowledge of internal medicine: a hypothesis-generating study of internal medicine residents. BMC Med Educ 2011, 11:5.

19. Daniels VJ, Kassam N: Determinants of internal medicine residents' choice in the Canadian R4 fellowship match: a qualitative study. BMC Med EduC 2011, 11:44

20. Horn L, Koehler E, Gilbert J, Johnson DH: Factors associated with the career choices of hematology and medical oncology fellows trained at academic institutions in the United States. J Clin Oncol 2011, 29:3932-3938

21. Watson $P$, Gaffney K: Factors influencing recruitment to rheumatology. Clin Med 2011, 11(5):509-510.

22. Brown SR: Q methodology and qualitative research. Qual Health Res 1996, 6:561-567

23. Cross RM: Exploring attitudes: the case for $\mathrm{Q}$ methodology. Health Educ Res 2005, 20(2):206-213.

24. PQMethod 2.11. Available at http://schmolck.userweb.mwn.de/qmethod/ downpqwin.htm. Accessed July 31, 2010.

25. McKeown B, Thomas D: Q methodology. Sage University paper series on quantitative applications in the social sciences, series no. 07-066. The international professional publishers. Beverly Hills: Sage Publications; 1988.

26. Van Exel N, Job A, de Graaf G: Q methodology: a sneak preview. 2005. Available from http://qmethod.org/tutoriallinks.php. Accessed May 5, 2010.
27. IBM Corp: Released: IBM SPSS statistics for windows, version 21.0. Armonk, NY: IBM Corp; 2012.

28. Ebell MH: Future salary and US residency fill rate revisited. JAMA 2008, 300(10):1131-1132.

29. Ghali WA, Greenberg PB, Mejia R, Otaki J, Cornuz J: International perspectives on general internal medicine and the case for "globalization" of a discipline. J Gen Intern Med 2006, 21(2):197-200.

30. McAlister FA: Why general internal medicine. CJGIM 2010, 5(1):5.

doi:10.1186/1472-6920-13-171

Cite this article as: Daniels and Kassam: Impact of personal goals on the internal medicine R4 subspecialty match: a Q methodology study. BMC Medical Education 2013 13:171

\section{Submit your next manuscript to BioMed Central and take full advantage of:}

- Convenient online submission

- Thorough peer review

- No space constraints or color figure charges

- Immediate publication on acceptance

- Inclusion in PubMed, CAS, Scopus and Google Scholar

- Research which is freely available for redistribution

Submit your manuscript at www.biomedcentral.com/submit
C Biomed Central 